\title{
MEDIACIÓN ESCOLAR: EN EL NIVEL MEDIO SUPERIOR
}

\author{
SCHOOL MEDIATION: AT THE MEDIA SUPERIOR LEVEL
}

\author{
Álvaro Pastor Castillo-Torres ${ }^{1}$ (D) \\ 1. Escuela Judicial del Estado de Tabasco, México. acastle27@hotmail.com \\ * Autor de correspondencia: Álvaro Pastor Castillo-Torres, correo electrónico: acastle27@hotmail.com
}

\section{RESUMEN}

El sistema educativo nacional en México contempla la educación básica, la educación media superior y la educación superior. El tema de interés en este documento es la importancia de la mediación escolar en el nivel medio superior conocido como bachillerato o preparatoria, este nivel prepara y forma a jóvenes estudiantes para el ingreso a la educación superior o universitaria. En ese tenor de formación a los estudiantes, es pertinente socializar las herramientas y técnicas de los mecanismos alternativos para la gestión y solución de conflictos en pro de una cultura de paz. La mediación escolar coadyuva al sistema educativo en la formación del estudiante toda vez que es una persona que está transitando a una edad adulta en el que adquiere mayor número de responsabilidades. Este tipo de mediación otorga a la comunidad estudiantil potencializar los espacios de convivencia reforzando el diálogo y comunicación con participación activa, plural y respeto.

Palabras clave: conflicto; cultura de paz; educación; mecanismos alternativos; violencia.

Cómo citar:

Castillo-Torres, Álvaro Pastor. (2021). Mediación escolar: en el nivel medio superior. Revista de Investigaciones Universidad del Quindio, 33(S2), 55-60. https://doi.org/10.33975/riuq. vol33nS2.612 


\begin{abstract}
The national educational system in Mexico includes basic education, upper secondary education and higher education. The subject of interest in this document is the importance of school mediation in the upper secondary level known as baccalaureate or preparatory, this level prepares and trains young students for admission to higher or university education. In this tenor of training students, it is pertinent to socialize the tools and techniques of alternative mechanisms for the management and resolution of conflicts in favour of a culture of peace. School mediation helps the educational system in the formation of the student since he is a person who is transitioning to an adult age in which he acquires a greater number of responsibilities. This type of mediation allows the student community to enhance the spaces for coexistence, reinforcing dialogue and communication with active, plural participation and respect.
\end{abstract}

Keywords: conflict; culture of peace; education; alternative mechanisms; violence.

\title{
INTRODUCCIÓN
}

En México con la reforma al sistema de justicia -hetero compositiva y auto compositiva- se provee de un marco legal, dentro del artículo 17 constitucional, que refiere que la ley promoverá en los justiciables, que las controversias sean tratadas a través de los mecanismos alternativos de solución de controversias, y se pretende que las escuelas se sirvan de las ventajas que ofrece la mediación para resolver los conflictos ya que además provee un marco para crear una cultura de paz. Como ciudadanos estamos formados con base a una serie de estructuras sociales, económicas, culturales, entre otros.

La educación formal e informal se conjugan en el crecimiento y desarrollo de toda persona; en ese sentido, la escuela es un centro de socialización, en donde muchas veces surgen discrepancias entre los mismos alumnos, alumnos-profesores, alumnos-administrativos, y por ende esto puede afectar el ambiente escolar y estropear el proceso de enseñanza; estos conflictos, son canalizados a las áreas administrativas del plantel educativo en donde conforme a lo que disponga el reglamento y de acuerdo a la acción cometida por la persona, regularmente se le asigna una sanción. Sin embargo, estos mecanismos no mitigan o previenen situaciones de conflictos, por lo que la propuesta de considerar la mediación escolar se aboca a establecer y afianzar la comunicación, empoderando y legitimando a las partes en conflicto para que asuman la responsabilidad de sus actos, además de divulgar la cultura de paz (Gerónimo et al, 2021) dentro y fuera del contexto escolar.

\section{METODOLOGÍA}

La educación formal es una actividad en la que la persona pasa un número de horas en el proceso de enseñanza-aprendizaje, es un entorno en el que se socializa, crean redes, expresan ideas, pensamientos. Sin embargo, al plantear ideas o realizar una acción en ocasiones no puede ser de agrado o satisfacción para una o varias personas, lo que propicia condiciones de diferencias, disputas, conflictos, violencia. En ese sentido, la revisión y descripción del alcance e implicación de la mediación escolar en la comunidad estudiantil permite dar un panorama de las ventajas de este mecanismo para procurar la aplicación y reproducción del mismo, en la solución de conflictos.

Para la comprensión de este tema se empleó el enfoque cualitativo con alcance descriptivo, analítico e 
interpretativo, se realizaron búsquedas de información bibliohemerográfica permitiendo identificar y exponer elementos sustantivos de la mediación escolar (concepto, alcance e implicaciones).

\section{RESULTADOS}

\section{Sistema educativo media superior}

El tipo Medio-Superior comprende el nivel de bachillerato, así como los demás niveles equivalentes a éste, y la educación profesional que no requiere bachillerato o sus equivalentes (SEP, 2021).
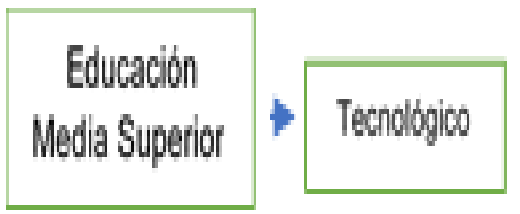
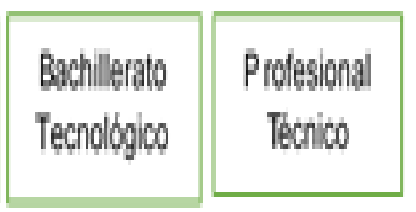

Fuente: SEP, 2021.

En México, para el ciclo escolar 2019-2020 del nivel medio superior, de acuerdo a datos del Instituto Nacional de Estadística y Geografía -INEGI- (2021) se tuvo una matrícula aproximada de 5144673 estudiantes. De ese universo de estudiantes, Tabasco registró una matrícula de 112440 alumnos de los cuales 57487 fueron hombres y 54953 eran mujeres.

\begin{tabular}{l|l|r|} 
Entidad federativa & Sexo & \multicolumn{1}{c|}{$\begin{array}{c}\text { 2019/2020 } \\
\text { Media superior }\end{array}$} \\
\hline Estados Unidos & Total & 5144673 \\
Mexicanos & Hombres & 2522207 \\
& Mujeres & 2622466
\end{tabular}

Fuente: INEGI, 2021.

Aunado a esa población estudiantil en una institución educativa se tiene al personal administrativo y docente. Como ya se ha señalado a partir de las relaciones sociales de la cotidianeidad en situaciones surgen problemas, mismos que pueden ser resueltos a través de la mediación escolar, lo cual otorga un panorama de la situación para prever, trabajar y gestionar factores que detonan el conflicto, así como a mitigar tales circunstancias, yendo en un proceso de comunidad estudiantil alineado a cambios de conducta, pensamiento y de comunicación con el afán de reforzar y crear una sociedad de convivencia respetuosa. Por lo anterior, en las siguientes líneas se describen aspectos-criterios, de la mediación escolar para visualizar las ventajas de integrarlo en el sistema educativo del nivel medio superior.

En ese sentido, la violencia escolar debe de ser entendida como aquella en la que existen múltiples elementos para su caracterización. Dado que la violencia no adopta una sola forma, ni se habla de ella en un solo sentido, resulta pertinente referirse a formas de violencia; todas ellas tienen como característica fundamental que se produce dentro del propio plantel educativo la cual es ejercida por sus miembros" (Prieto et al., 2005). Al ser una controversia multifactorial la mediación escolar puede atender de forma integral y sostenible la formación como pares facilitadores. 


\section{Mediación escolar}

"El estilo de mediación centrado en los estudiantes constituye una respuesta pedagógica idónea para formar estrategias de autorregulación que garanticen la resolución pacífica de los conflictos; entonces las instituciones educativas y la familia constituyen espacios para afrontar de forma democrática los conflictos surgidos, sino también ir configurando una cultura de la convivencia. La aplicación de normativas disciplinares antes que la mediación constituye estrategias paliativas que ocasionan resentimientos, discusiones, inconformidad limitando el desarrollo de habilidades emocionales para resolver los problemas.” (Merchán et al., 2019, p. 401). El autor plantea la importancia de la educación formal (plantel educativo) y la informal (casa, amigos, entre otros) como indivisible e interdependiente, ya que en el momento que uno se vulnere el otra carga con la responsabilidad.

La mediación escolar es un procedimiento para resolver conflictos, "capaz de realizar una formación continua y progresiva con los integrantes de la comunidad estudiantil con el afán establecer una convivencia desde la reciprocidad, la cooperación, la responsabilidad social, además de propiciar un buen ambiente de convivencia y recuperar el sentido de comunidad" (Ibarrola \& Iriarte, p. 368).

La mediación escolar -actualmente en plena expansión- contiene aspectos formativos afectivos y sociales, esto es, herramientas que atienden a las personas individualmente y a la institución en la que conviven.

En este sentido la mediación favorece la vinculación afectiva del alumnado con el colegio al establecer cauces participativos, interés en las relaciones interpersonales, proyectos comunes entre profesores/as y alumnos/as, atendiendo la diversidad y facilitando la gestión de las normas de disciplina. Se asocia a marcos de convivencia que generan formas positivas de sentir, de pensar y actuar

\section{Principios}

La mediación escolar constituye una significativo labor preventiva y formativa de forma individual y colectiva. En ese sentido, un aspecto importante para este tipo de mediación es que se guíen de los principios que rigen los mecanismos alternativos, los cuales se describen a continuación.

- Voluntariedad. Por decisión propia sin coacción alguna ambas partes disponen estar y llevar a efecto el proceso de mediación escolar.

- Neutralidad. El mediador escolar no se inclinará o dará favoritismo a alaguna de las partes.

- Imparcialidad. El proceso se lleva a cabo de forma objetiva evitando emisión de juicios, opinión o prejuicio (DOF, 2014).

- Equidad. Determina condición de equilibrio entre las partes.

- Confidencialidad. La información que se aborda en el proceso no serpa divulgada.

- Personalísimo. Ambas partes deben estar presentes al igual que el mediador escolar.

- Información. Se informa a las partes los alcances del proceso, consecuencias.

- Honestidad. Las partes y el mediador escolar deberán conducirse apegados a la verdad.

\section{Alcances e implicaciones}

En cuanto a temas de no violencia y cultura de paz en el sector educativo, la Ley de Educación (DOF, 2019) en México dispone: 
“Artículo 74. Las autoridades educativas, en el ámbito de su competencia, promoverán la cultura de la paz y no violencia para generar una convivencia democrática basada en el respeto a la dignidad de las personas y de los derechos humanos. Realizarán acciones que favorezcan el sentido de comunidad y solidaridad, donde se involucren los educandos, los docentes, madres y padres de familia o tutores, así como el personal de apoyo y asistencia a la educación, y con funciones directivas o de supervisión para prevenir y atender la violencia que se ejerza en el entorno escolar." $\ldots$

"IX. Elaborar y difundir materiales educativos para la prevención y atención de los tipos y modalidades de maltrato escolar, así como coordinar campañas de información sobre las mismas." "Las autoridades educativas, en el ámbito de sus respectivas competencias, emitirán los lineamientos para los protocolos de actuación que sean necesarios para el cumplimiento de este artículo, entre otros, para la prevención y atención de la violencia que se genere en el entorno escolar, familiar o comunitario contra cualquier integrante de la comunidad educativa, para su detección oportuna y para la atención de accidentes que se presenten en el plantel educativo. A su vez, determinarán los mecanismos para la mediación y resolución pacífica de controversias que se presenten entre los integrantes de la comunidad educativa"

La mediación escolar permite a la comunidad estudiantil un proceso de enseñanza aprendizaje que impacte de forma pronta, pero más allá del ramo educativo se forma futuros ciudadanos que tengan la capacidad y responsabilidad de asumir la responsabilidad de sus actos.

Un aspecto a considerar es trabajar con teorías de aprendizaje que afiancen los principios de los mecanismos, "las teorías del aprendizaje cooperativo aportan la posibilidad de enseñar al alumnado a cooperar y a colaborar" (Pulido et al., 2013). En ese mismo sentido, divulgar y reproducir los procesos restaurativos permite a la comunidad integrarse y considerar aquellos elementos o factores que motivan a que el integrante de su comunidad haya cometido, omitido una acción no favorable.

Reproducir este tipo de mediación, conlleva a que los jóvenes integren en su vida cotidiana elementos de empoderamiento y legitimidad para resolver sus conflictos.

"Es indispensable que coexista dinámica entre la Cultura de la Paz y la Educación, ya que esta es un hecho social que transforma a los individuos y da pauta a la construcción de nuevos modelos que guían la vida académica y ciudadana dando nuevos significados culturales, encaminados a la erradicación de ambientes violentos y poco tolerables a las diferencias individuales" (Quintero, 2020).

Se trabaja hacia una sociedad del futuro que respete y tolere la diversidad de opiniones, que mediante la pluralidad se llegue a consensos y escucha activa, una sociedad democrática.

En la dinámica de transición como sociedad a través de la educación formal e informal, vamos tornando la idea de conflicto (Pérez \& Gutiérrez, 2016) como un proceso de transformación y no como algo negativo. Da pauta a considerar e identificar que existe una situación en la que se debe discutir de forma productiva atendiendo a los intereses y necesidades de los involucrados, así como velar por el bien colectivo. 


\section{DISCUSIÓN}

Los problemas de convivencia en los planteles educativo, demandan acciones estratégicas globales que atiendan y respondan a la demanda del contexto de acuerdo a sus necesidades. La participación activa de todos los integrantes de la comunidad, así como la disposición de la institución o instituciones llevan a construir una sociedad tangible e intangible en mecanismos alternativos y cultura de paz; se puede decir que de manera tangible que a través de la apertura de las instancias encargadas del sector educativo se debe poner atención a la infraestructura y condiciones en las que se llevan a cabo las sesiones de clase, así como de forma externa.

Una buena convivencia estimula una cultura de paz y concordia que respeto las estructuras e instituciones sociales para permanecer en un estado de orden sano.

\section{REFERENCIAS}

1. Diario Oficial de la Federación. (2019). Ley de Educación. México.

2. Diario Oficial de la Federación. (2014). Ley Nacional de Mecanismos Alternativos de Solución de Controversias en materia Penal. México.

3. González, Paulino Gerónimo; Silva Hernández, Francisca y Martínez Prats, Germán. (2021). Mecanismos alternativos en la solución de conflictos para la construcción de una cultura de paz. Revista Ciencias de la Documentación, 7(1), 15-23.

4. Ibarrola-García, Sara, \& Iriarte Redín, Concha (2013). La influencia positiva de la mediación escolar en la mejora de la calidad docente e institucional: percepciones del profesor mediador. Profesorado. Revista de Currículum y Formación de Profesorado, 17(1),367-384.

5. INEGI. (2021). Matrícula escolar por entidad federativa según nivel educativo, ciclos escolares seleccionados 2000/2001 a 2019/2020.

6. Merchán Gavilánez, M. L., Cadena Alvarado, R., \& Napa Yance, C. (2019). La mediación de conflictos escolares. Incidencia en el desarrollo de la inteligencia emocional. Revista Conrado, 15(69), 399-404.

7. Pérez-Archundia, Eduardo, \& Gutiérrez-Méndez, David (2016). El conflicto en las instituciones escolares. Ra Ximhai, 12(3),163-180

8. Pulido, Rosa, Martín Seoane, Gema \& Molina Beatriz Lucas. (2013). Orígenes de los Programas de Mediación Escolar: Distintos enfoques que influyen en esta práctica restaurativa. Anales de Psicología, 29(2),385-392.

9. Prieto Quezada, María Teresa, Carrillo Navarro, José Claudio, \& Jiménez Mora, José. (2005). La violencia escolar. Un estudio en el nivel medio superior. Revista mexicana de investigación educativa, 10(27), 1027-1045.

10. Quintero López, Irma. (2020). Gestión de conflictos y mediación escolar en alumnos de la licenciatura en ciencias de la educación como herramientas para el desarrollo de una cultura de la paz. Conrado, 16(72), 123-130.

11. SEP. (2021). La educación media superior en el sistema educativo nacional. Subsecretaria de Educación Media Superior: México. 